\title{
BMJ Open Long-term mortality in young and middle-aged adults hospitalised with chronic disease: a Danish cohort study
}

\author{
Nils Skajaa (D) , Anne Gulbech Ording, Bianka Darvalics, Erzsebet Horvath-Puho, \\ Henrik Toft Sørensen
}

To cite: Skajaa N, Ording AG, Darvalics B, et al. Long-term mortality in young and middleaged adults hospitalised with chronic disease: a Danish cohort study. BMJ Open 2020;10:e038131. doi:10.1136/ bmjopen-2020-038131

- Prepublication history and additional material for this paper is available online. To view these files, please visit the journal online (http://dx.doi.org/10. 1136/bmjopen-2020-038131).

NS and AGO are joint first authors.

Received 28 February 2020 Revised 23 August 2020 Accepted 10 September 2020

\section{A) Check for updates}

(C) Author(s) (or their employer(s)) 2020. Re-use permitted under CC BY-NC. No commercial re-use. See rights and permissions. Published by BMJ.

Department of Clinical Epidemiology, Aarhus University Hospital, Aarhus, Denmark

Correspondence to

Mr Nils Skajaa;

nilsskajaa@clin.au.dk

\section{ABSTRACT}

Objectives To examine the long-term outcomes for patients hospitalised with chronic diseases at age 30, 40 or 50 years.

Design Nationwide, population-based cohort study. Setting All Danish hospitals, 1979-1989, with follow-up through 2014.

Participants Patients hospitalised during the study period with one, two or three or more chronic diseases and age-matched and sex-matched persons from the general population without chronic disease leading to hospitalisation: age-30 group: 13857 patients and 69285 comparators; age-40 group: 24129 patients and 120645 comparators; and age-50 group, 37807 patients and 189 035 comparators.

Main outcome measures Twenty-five-year mortality risks based on Kaplan-Meier estimates, years-of-life-lost (YLLs) and mortality rate ratios based on Cox regression analysis. YLLs were computed for each morbidity level, as well as in strata of income, employment, education and psychiatric conditions.

Results Twenty-five-year mortality risks and YLLS increased steadily with increasing number of morbidities leading to hospitalisation and age, but the risk difference with general population comparators remained approximately constant across age cohorts. In the age-30 cohort, the risk differences for patients compared with comparators were $35.0 \%$ (95\% Cl 32.5 to 37.5$)$ with two diseases and $62.5 \%$ (54.3\% to $70.3 \%$ ) with three or more diseases. In the age-50 cohort, these differences were, respectively, $48.4 \%$ (47.4 to 49.3 ) and $61.7 \%$ (60.1\% to $63.0 \%$ ). Increasing morbidity burden augmented YLLS resulting from low income, unemployment, low education level and psychiatric conditions. In the age-30 cohort, YYLs attributable to low income were 2.4 for patients with one disease, 6.2 for patients with two diseases and 11.5 for patients with three or more diseases.

Conclusions Among patients with multiple chronic diseases, the risk of death increases steadily with the number of chronic diseases and with age. Multimorbidity augments the already increased mortality among patients with low socioeconomic status.

\section{INTRODUCTION}

Multimorbidity, or the coexistence of two or more chronic conditions within the same individual, ${ }^{1}$ is common among young and

\section{Strengths and limitations of this study}

- This nationwide, population-based cohort study examined the long-term mortality risks among patients of age 30,40 or 50 years with and without hospital-diagnosed chronic disease.

- The study furthermore examined how number of chronic diseases impacts mortality and how socioeconomic factors and other psychiatric disease impacts these risks.

- The setting with long-term follow-up and accurate linkage within a uniform healthcare system eliminated selection and referral biases.

- Data on chronic and psychiatric diseases arose from inpatient hospitalisations and thus did not include conditions diagnosed and treated in the outpatient setting.

- Patients were identified based on 19 selected chronic diseases included in the Charlson Comorbidity Index, but other chronic conditions not listed here could potentially affect long-term outcomes.

middle-aged adults. ${ }^{2}$ A Scottish cross-sectional study established that despite a strong association of multimorbidity with increasing age, adults aged 65 years or younger account for most of these patients in absolute numbers. ${ }^{2}$ Multimorbidity is associated with fractionated healthcare and adverse health outcomes such as poor survival and reduced quality of life..$^{3-5}$

Strong evidence exists that multimorbidity is associated with premature death; however, most previous studies examining this association have focused on older adults. ${ }^{3} 6-10$ For example, in a recent meta-analysis of evidence pooled from 26 studies, risk of death was increased approximately twofold among multimorbid patients over age 60 years compared with those without multimorbidity. ${ }^{3}$ In contrast, the long-term prognosis of young and middle-aged adults age 50 years or younger who have multimorbidity remains poorly understood. The lack of focus on this population is worrisome, considering their potentially long life expectancy and the huge 
personal and societal consequences of multimorbidity in this age group. ${ }^{21}$ Furthermore, data indicate a strong socioeconomic gradient in the onset of multimorbidity, particularly among young and middle-aged adults, ${ }^{2}{ }^{12}$ with little information about how this gradient affects long-term prognosis.

To address these evidence gaps, we used nationwide health and administrative registries with virtually complete individual-level linkage and follow-up to examine 25-year mortality risks and expected years of life lost (YLLs) in three cohorts of patients aged 30, 40 and 50 years hospitalised with one or more chronic diseases.

\section{METHODS}

\section{Design and setting}

We conducted a nationwide, population-based cohort study in Denmark covering 1979-1989, allowing for a 25-year follow-up period through 2014. The Danish National Health Service provides universal, tax-supported healthcare for all Danish residents to both general practitioners and hospital care. ${ }^{13}$ Patient data are linkable at the individual-level across health and administrative registries through a unique 10-digit identifier, assigned by the Civil Registration System (CRS) to all residents at birth or on immigration. ${ }^{14}$ The CRS is updated daily concerning changes in vital status and migration for the entire Danish population.

\section{Patient cohorts}

We used the Danish National Patient Registry (DNPR) to construct three cohorts of different ages at baseline: we identified those ages 30,40 or 50 years with a primary or secondary inpatient hospital diagnosis of at least one condition included in the Charlson Comorbidity Index (CCI) ${ }^{15}$ We categorised the overall morbidity burden according to the number of diagnosed conditions (1, 2 or $\geq 3)$. Patients with at least two conditions were defined as having multimorbidities. The baseline was set as the date a patient reached age 30,40 or 50 years. The cumulative source population during the inclusion period was 898 266 for people aged 30 years; 871658 for people aged 40 years; and 627826 for people aged 50 years.

The DNPR has recorded non-psychiatric inpatient hospitalisations since $1977 .{ }^{16}$ Records of hospitalisations in the DNPR include one primary and one or more secondary diagnosis, coded according to the International Classification of Diseases, Eighth Revision, between 1977 and 1994 and 10th Revision thereafter. The CCI is a commonly used index to identify comorbidities and comprises a wide range of diseases, including cardiovascular, metabolic, hepatic and renal diseases, malignancies, dementia, peptic ulcer and AIDS (online supplemental table S1) ${ }^{15}$ Hospital diagnosis codes of CCI conditions have high validity in the DNPR, with positive predictive values for all CCI conditions exceeding 90\% compared with medical records. ${ }^{17}$

\section{General population comparison cohorts}

We used the CRS to construct three general population comparison cohorts. ${ }^{14}$ For this purpose, we matched, with replacement, up to five persons from the general population to each member of the patient cohorts on date of birth and sex. ${ }^{18}$ Persons were ineligible if they had one or more primary or secondary inpatient hospital diagnoses of any CCI conditions recorded in the DNPR any time before or at baseline. Diagnoses made after baseline were ignored.

\section{Mortality}

The primary outcome was time to death during 25 years of follow-up. Data on all-cause mortality were extracted from the CRS.

\section{Covariables}

To examine the impact of socioeconomic factors, we gathered information on socioeconomic factors 2 years before baseline: income level (low, intermediate, high and very high), employment status (early retirement, unemployed and employed) and education level (primary school, youth education/high school and higher education) from the Integrated Database for Labor Market Research. ${ }^{19}$ We also gathered information on prevalent psychiatric conditions at baseline (schizophrenia, bipolar disorder/depression, schizotypal disorder, personality disorder and other mental illness) from the Psychiatric Central Research Registry (PCRR).$^{20}$ The PCRR contains data on all inpatient psychiatric admissions since 1969.

\section{Statistical analysis}

We characterised patients and their matched general population comparators according to age, sex, calendar year, morbidity burden, individual chronic diseases included in the CCI, income level, employment status, educational achievement and psychiatric conditions. We followed cohort members from baseline until death, emigration or 31 December 2014, whichever occurred first. Separately for each age cohort, we used the complement of the Kaplan-Meier estimator to compute and illustrate 25-year mortality risks for patients, stratified by their morbidity burden and general population comparators.

As an additional method to assess survival in the patient and the general population cohorts, we computed expected YLLs as the mean survival difference between the two, that is, the difference in the area between the mean Kaplan-Meier survival curves. ${ }^{21}$ YLLs were computed for each morbidity level, as well as in strata of income, employment and education, and for each psychiatric condition, without and with stratifying by morbidity level. Ninety-five per cent CIs were computed using bootstrapping on each of the matched pairs using 100 replicates.

As a measure of the mortality rate ratio, we computed HRs of death and 95\% CIs by means of stratified Cox proportional hazards regression within the sex-matched and age-matched strata, comparing the patient cohorts with the general population comparison cohorts. 
Table 1 Characteristics of Danish patients with one or more chronic diseases leading to hospitalisation by age 30,40 or 50 years and age-matched and sex-matched individuals from the general population without chronic disease during 1979-1989

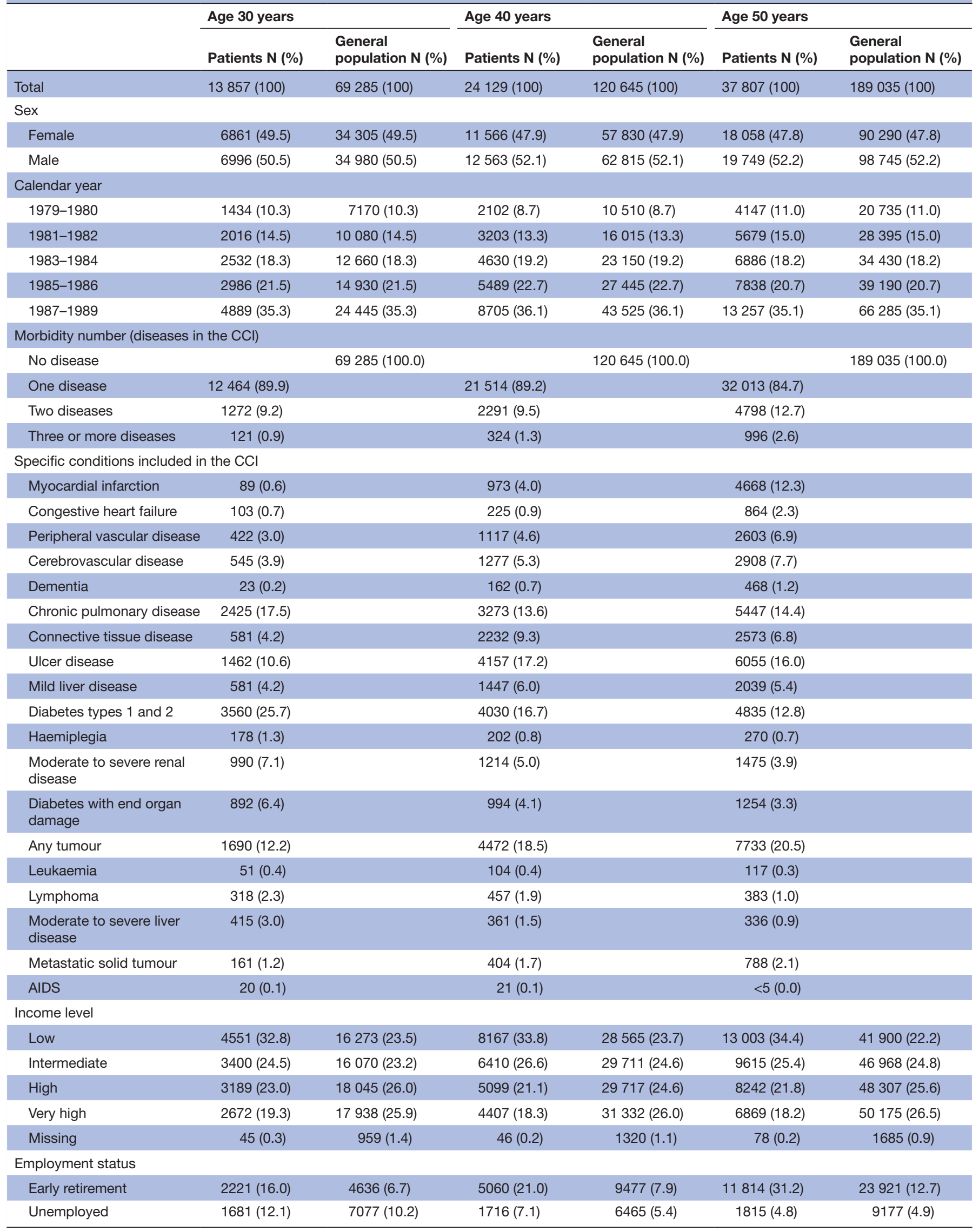


Table 1 Continued

\begin{tabular}{|c|c|c|c|c|c|c|}
\hline & \multicolumn{2}{|l|}{ Age 30 years } & \multicolumn{2}{|l|}{ Age 40 years } & \multicolumn{2}{|l|}{ Age 50 years } \\
\hline & Patients N (\%) & $\begin{array}{l}\text { General } \\
\text { population N (\%) }\end{array}$ & Patients N (\%) & $\begin{array}{l}\text { General } \\
\text { population N (\%) }\end{array}$ & Patients N (\%) & $\begin{array}{l}\text { General } \\
\text { population N (\%) }\end{array}$ \\
\hline Missing & $197(1.4)$ & $2049(3.0)$ & $259(1.1)$ & $2823(2.3)$ & $364(1.0)$ & $3299(1.7)$ \\
\hline \multicolumn{7}{|l|}{ Educational achievement } \\
\hline Primary school & 5525 (39.9) & 22463 (32.4) & $10320(42.8)$ & 41956 (34.8) & 20708 (54.8) & 93209 (49.3) \\
\hline Higher education & $2153(15.5)$ & 13369 (19.3) & $3690(15.3)$ & $24571(20.4)$ & 3879 (10.3) & $26664(14.1)$ \\
\hline Missing & $716(5.2)$ & $4450(6.4)$ & $831(3.4)$ & $5229(4.3)$ & $1129(3.0)$ & $6388(3.4)$ \\
\hline \multicolumn{7}{|l|}{ Psychiatric conditions } \\
\hline Schizophrenia & $102(0.7)$ & $327(0.5)$ & $208(0.9)$ & $626(0.5)$ & $303(0.8)$ & $952(0.5)$ \\
\hline Personality disorders & $743(5.4)$ & $1411(2.0)$ & $2110(8.7)$ & $3476(2.9)$ & $3181(8.4)$ & $6182(3.3)$ \\
\hline Other mental illness & $1430(10.3)$ & $2102(3.0)$ & $3400(14.1)$ & 4107 (3.4) & 5096 (13.5) & $6888(3.6)$ \\
\hline
\end{tabular}

$\mathrm{CCl}$, Charlson Comorbidity Index.

The regression was done separately in each morbidity subgroup. In multivariable analyses, we adjusted for income level, employment status and education level. Because the proportionality assumption was violated, we applied a piecewise Cox regression, computing HRs within $0-1$ year, $>1-5$ years, $>5-10$ years, $>10-20$ years and $>20-25$ years.

All statistical analyses were conducted using the SAS statistical software package, V.9.4. Diagnosis codes are provided in online supplemental table S1.

\section{Patient involvement}

No patients were involved in setting the research question or the outcome measures, nor were they involved in developing plans for design or implementation of the study. No patients were asked to advise on interpretation or writing up of results. There are no plans to disseminate the results of the research to study participants or the relevant patient community.

\section{RESULTS}

We identified 13857 patients and 69285 age-matched and sex-matched general population comparators who were age 30 years; 24129 patients and 120645 age-matched and sex-matched comparators who were age 40 years; and 37807 patients and 189035 age-matched and sexmatched comparators who were age 50 years (table 1 ). The sexes were approximately equally distributed in each cohort. The prevalence of multimorbidity increased slightly with age. The most frequently hospital-diagnosed conditions were any tumour, peptic ulcer, chronic pulmonary disease and type 1 and 2 diabetes. Socioeconomic status was generally lower in the patient cohorts, and across all age cohorts, low income, unemployment and early retirement, and less educational achievement was more frequent among patients than among general population comparators. Similarly, psychiatric conditions, such as personality disorder and other mental illness, were more common among the patients than among the comparators.

\section{Absolute mortality risks}

We observed 2999 deaths in the age-30 group, 8988 in the age-40 group and 23427 deaths in the age-50 group. The 25-year mortality risk increased steadily with increasing number of morbidities leading to hospitalisation and age (figure 1). Among patients with one disease, the 25-year mortality risks were $19.4 \%$ (95\% CI $18.7 \%$ to $20.1 \%$ ) in the age-30 group, $34.4 \%$ (95\% CI $33.7 \%$ to $35.0 \%$ ) in the age- 40 group and $58.6 \%$ (95\% CI $58.1 \%$ to $59.2 \%$ ) in the age- 50 group. These risks increased respectively to $68.6 \%$ (95\% CI $60.3 \%$ to $76.6 \%$ ), $82.3 \%$ (95\% CI $78.0 \%$ to $86.3 \%$ ) and $92.4 \%$ (95\% CI $90.6 \%$ to $93.9 \%)$ among patients with three or more diseases at baseline. However, the mortality risk differences with matched comparators from the general population remained largely similar across age cohorts. For the age-30 patients at baseline, the risk differences with comparators were $13.3 \%$ (95\% CI $12.8 \%$ to $13.8 \%$ ) with one disease, $35.0 \%$ (95\% CI $32.5 \%$ to $37.5 \%)$ with two diseases and $62.5 \%$ (95\% CI $54.3 \%$ to $70.3 \%$ ) with three or more diseases. For the age-40 patients, the risk differences with matched comparators were $21.3 \%$ (95\% CI $20.9 \%$ to $21.7 \%$ ) with one disease, $46.8 \%$ (95\% CI $44.9 \%$ to $48.6 \%$ ) with two and $69.2 \%$ (95\% CI $65.1 \%$ to $73.0 \%$ ) with three or more. Finally for the age-50 group, the risk differences 

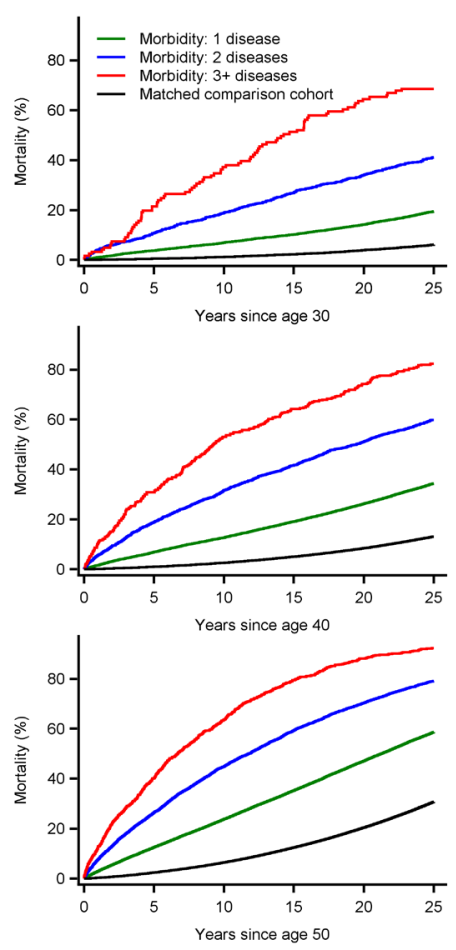

Figure 1 Twenty-five-year mortality risks for patients with one or more chronic diseases when they reached age 30, 40 or 50 years, stratified by number of chronic conditions and age-matched and sex-matched individuals from the general population without chronic disease during 1979-1989 in Denmark.

from matched comparators were $28.0 \%$ (95\% CI $27.6 \%$ to $28.3 \%), 48.4 \%$ (95\% CI $47.4 \%$ to $49.3 \%$ ) and $61.7 \%$ (95\% CI $60.1 \%$ to $63.0 \%)$ with one two, and three or more diseases, respectively.

\section{Years of life lost}

We calculated expected YLLs by comparing the mean survival difference between the patient and general population cohorts. In line with the absolute mortality risks, expected YLLs during 25 years of follow-up increased with baseline age and with number of morbidities. For patients in the 30-year age group, the expected YLLs were 1.7 (95\% CI 1.6 to 1.8$), 5.2$ (95\% CI 4.7 to 5.6 ) and 10.4 (95\% CI 8.7 to 12.1 ) with one, two and three or more diseases, respectively. For those in the 50-year group, the corresponding YLLs were 4.6 (95\% CI 4.5 to 4.7 ), $9.3(95 \%$ CI 9.1 to 9.6$)$ and 13.4 (95\% CI 12.9 to 13.9$)$ (table 2).

YLLs were greater among patients with low versus high income, for those on early retirement versus being employed and for those with lower versus higher education level (table 2). For example, YLLs for patients who were aged 30 years and with low income were as high as or higher than those for patients with very high income who were 10 years older. For psychiatric conditions, YLLs were substantial for the patient groups (eg, with schizophrenia, the YLLs were 3.6 (95\% CI 1.8 to 5.5$)$ in the age-30 cohort and 6.1 (95\% CI 5.0 to 7.2$)$ in the age-50 cohort).

YLLs in association with lower socioeconomic status and psychiatric conditions were more pronounced with increasing morbidity burden, regardless of age (table 2). For example, in the age-30 cohort, YYLs because of low income were 2.4 (95\% CI 2.2 to 2.6) for patients with one disease, 6.2 (95\% CI 5.3 to 7.2) for patients with two diseases and 11.5 (95\% CI 8.2 to 14.8) for patients with three or more diseases. Similar trends were observed for most other socioeconomic factors and psychiatric conditions.

\section{Relative mortality risks}

Compared with sex-matched and age-matched comparators from the general population, the relative risk of death during the first year was approximately 20-100 fold in patients with multimorbidity (table 3). Although the HRs decreased during follow-up, values ranging from approximately $2-10$, depending on baseline age, persisted among patients surviving at least 20 years. HRs tended to decrease with increasing baseline age, irrespective of number of morbidities and follow-up period. Adjustment for socioeconomic factors did not change the unadjusted estimates materially.

\section{DISCUSSION}

In this nationwide, population-based cohort study comprising patients age 30, 40 and 50 years, the 25-year mortality risk grew with increasing number of morbidities leading to hospitalisation and with age. Although the mortality risk difference with persons from the general population increased among patients with more chronic conditions, it remained approximately constant across age cohorts. Increasing number of morbidities was linked to higher YLLs from low income, unemployment, low education level and psychiatric conditions.

Our study should be viewed in light of several factors. Our setting with long-term follow-up and accurate linkage within a uniform healthcare system eliminated selection and referral biases. However, data on chronic and psychiatric conditions arose from inpatient hospitalisations and thus did not include conditions diagnosed and treated in the outpatient setting, including by general practitioners. Presumably, this selection yielded higher mortality risk estimates than would have resulted with inclusion of outpatient diagnoses. It is possible that general population comparators were, in fact, living with chronic conditions not leading to hospitalisation. This potential source of misclassification could have biased the HRs downwards. Furthermore, we identified and categorised patients based on 19 selected chronic diseases included in the CCI, and other chronic conditions not listed here could potentially affect prognosis. In addition, prognoses associated with several of the included conditions, including myocardial infarction, stroke, some cancers, AIDS and leukaemia have 


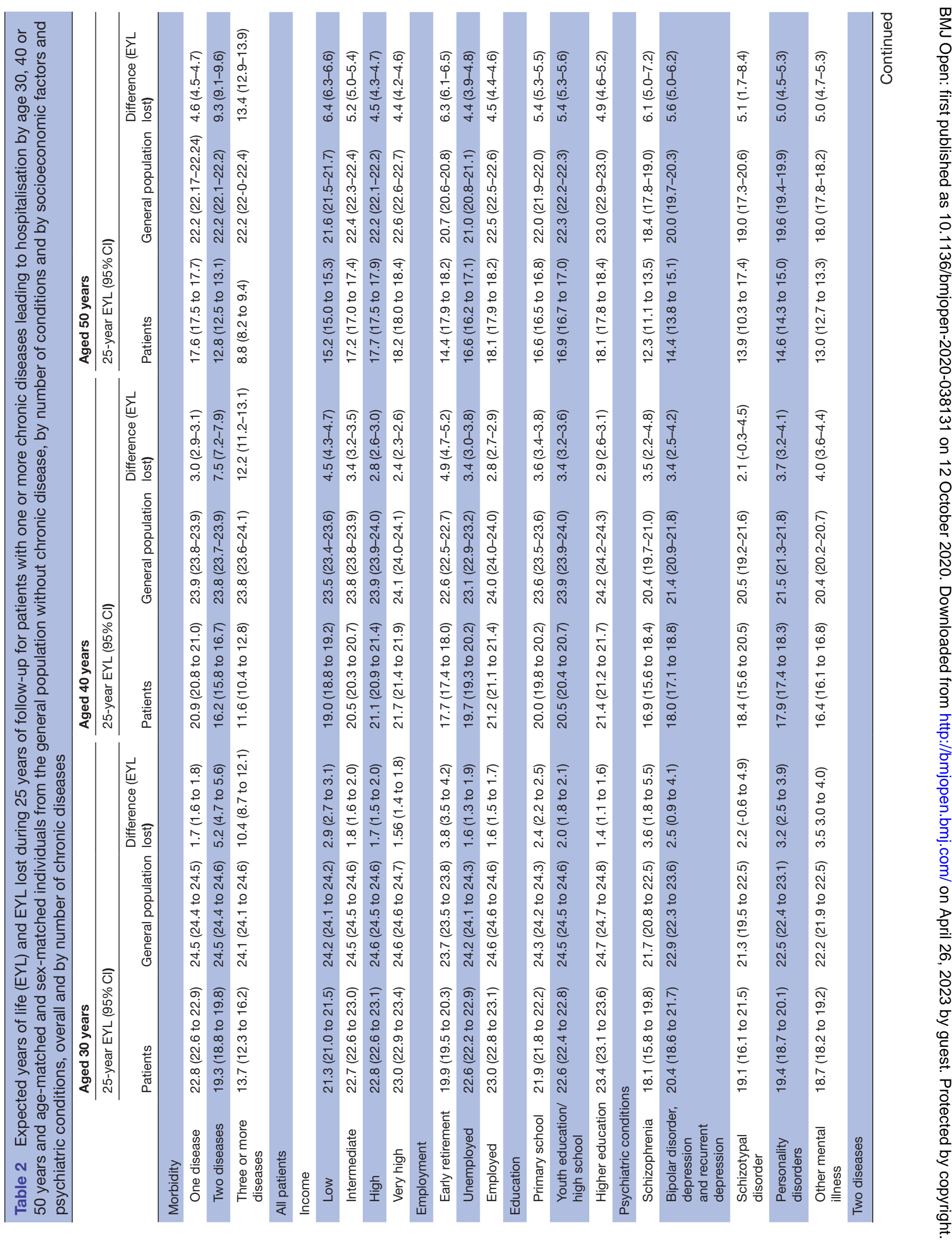




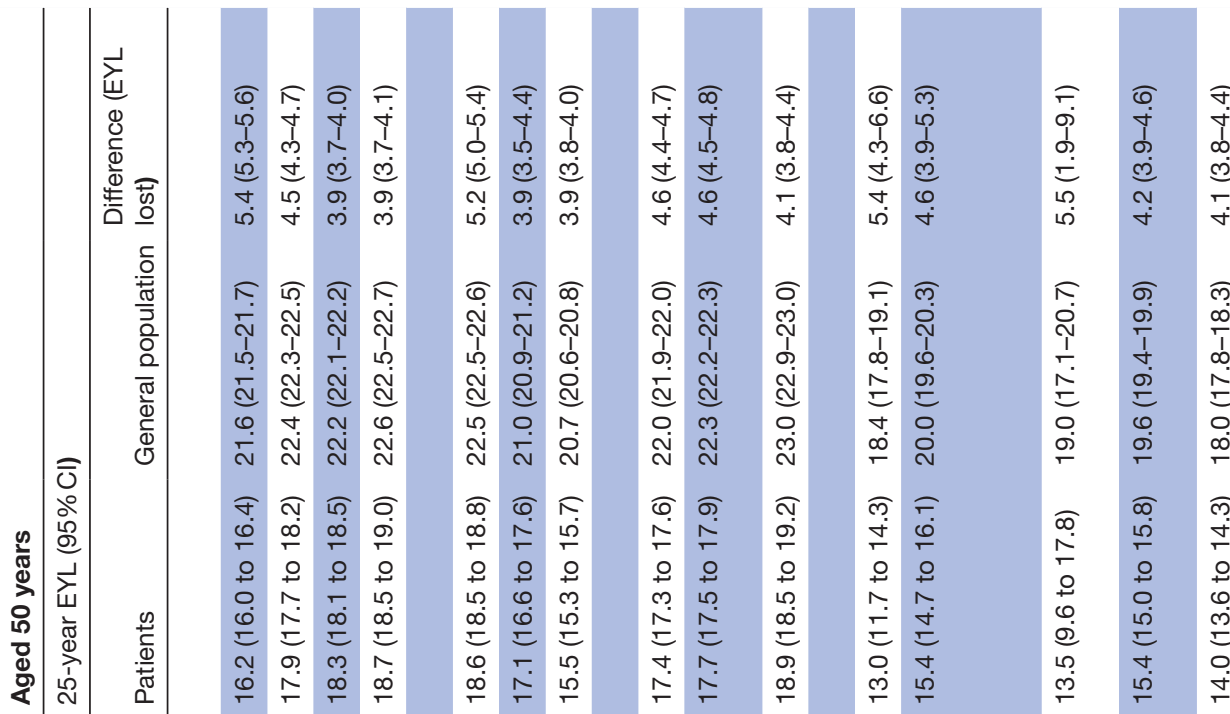

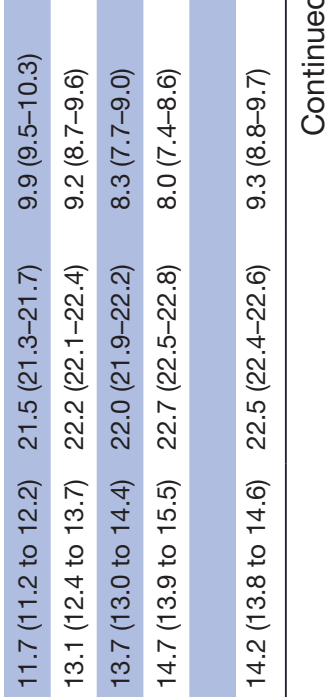

๘

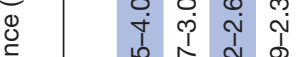

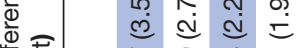

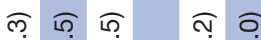
ก) लृ @ِ 1 âd 青哭 $\stackrel{\square}{\square} \underset{\sim}{\nabla}$ 일 $\stackrel{\text { ㄱ }}{2}$

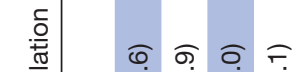

กั่

ल क

0

กั กั กั

ๆ 0 क

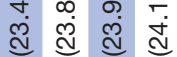

ป $\cong$

ले $\stackrel{\text { ले }}{\mathrm{N}}$

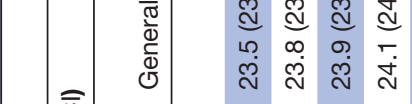

ปั

0

อ

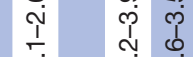

¿ู

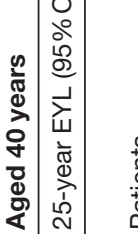

ชิ สุ

क เก क

กิ $\bar{ก}$ กั่

离

ஸे

ก่

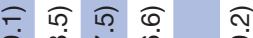

$\begin{array}{lllll}p & 0 & 0 & 0 \\ 1 & 1 & 0 & 0 & 0 \\ 0 & 0 & 0 & 0\end{array}$

$\pm=$ 递

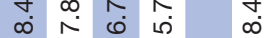

ฮุ ศุ ชุ

ஸ் ஸ்

@ָ

में

ก N $N$

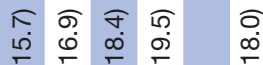

+ 웅ㅇㅇㅇ 웅

$\begin{array}{llll}0 & 0 & 0 & 0 \\ 0 & \infty & m & \infty \\ 0\end{array}$

+ 우 $ᄋ$

क़ ल

ড়

$\circ$ 웅

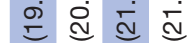

ป ᄃ

ウீ

స.

穴

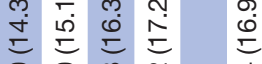

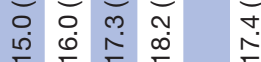

离

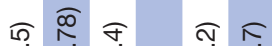

ตุ ตํ ติ

สุ ชิ กิ

\%

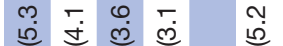

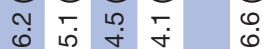

จ $\widehat{0} \widehat{0} \widehat{ก}$

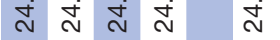

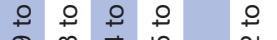

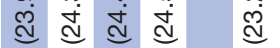

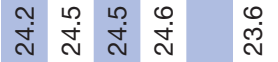

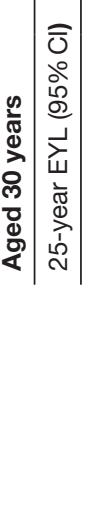

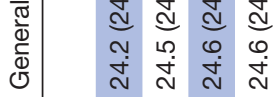

@્d

กิ่ ป

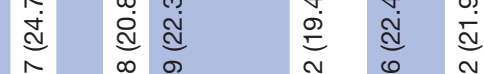

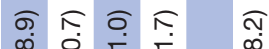

$\stackrel{\infty}{\infty} \dot{\sim} \overline{\mathrm{N}}$

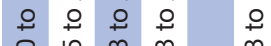

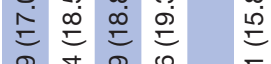

穴 


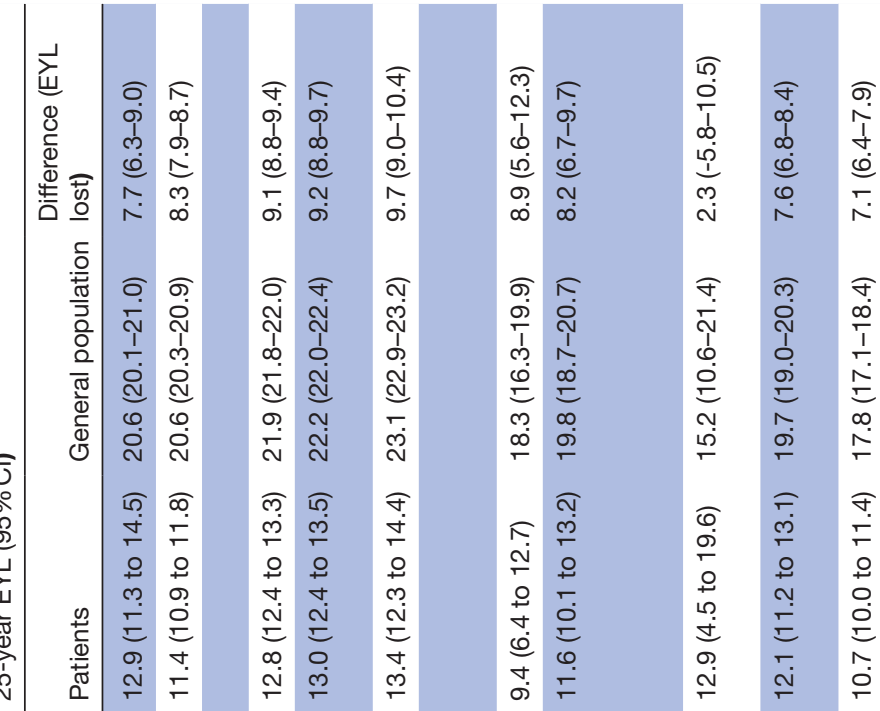

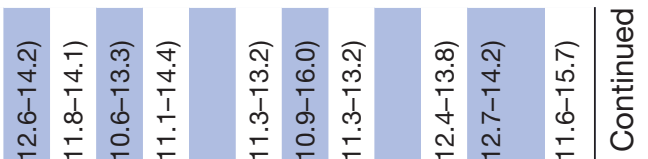

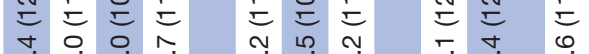

m্j

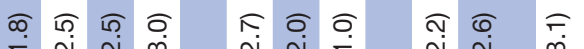

กิ กิ กิ กิ่

क

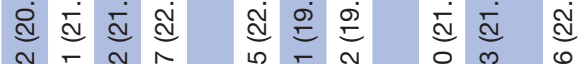

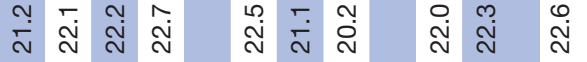

$\frac{\overline{0}}{\frac{0}{\bar{F}}}$

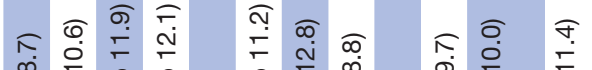

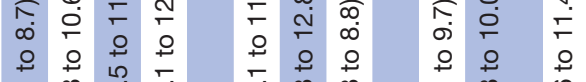

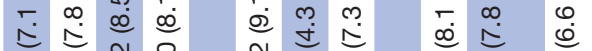

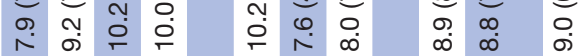

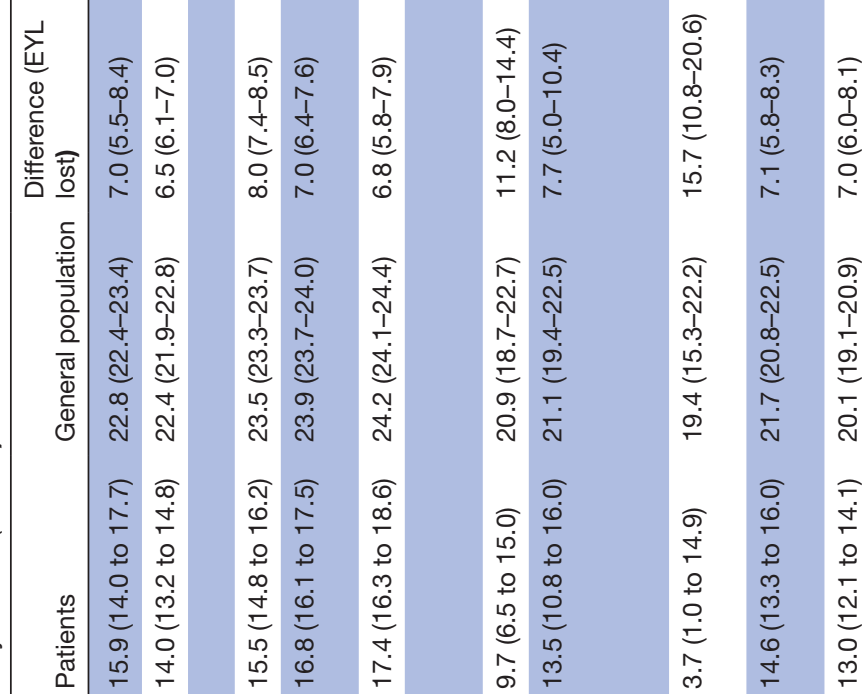

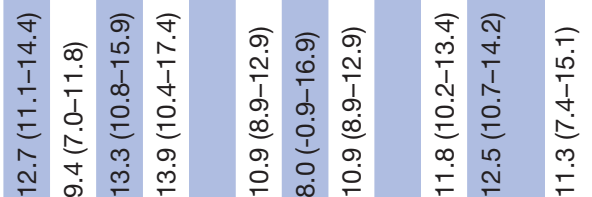

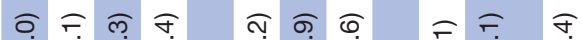

交

స̂.

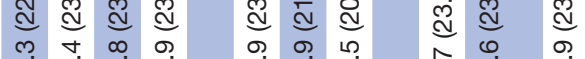

๙

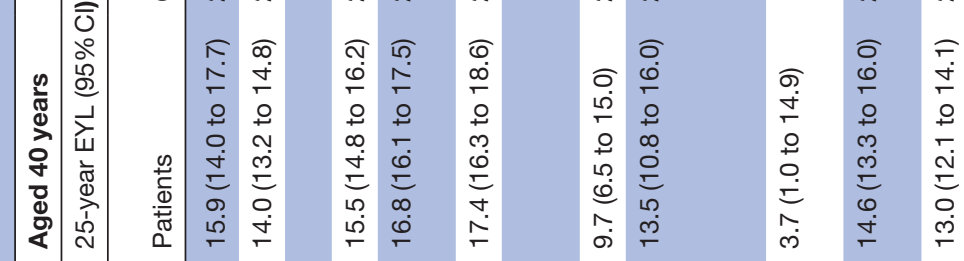

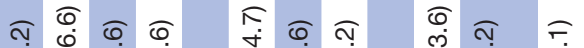

彳亍

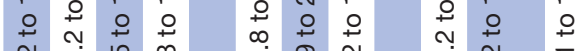

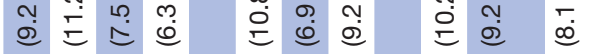

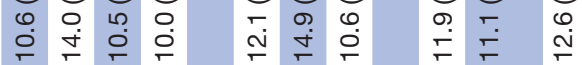

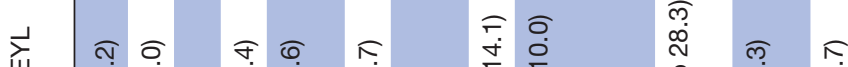

ब बढ व का

咅

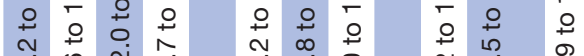

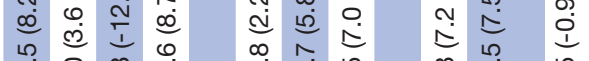

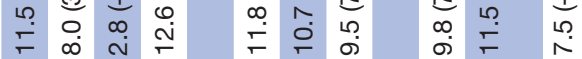

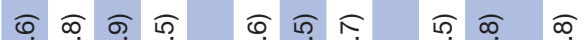

ป

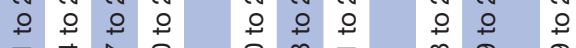

लू山

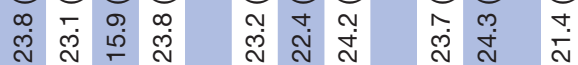

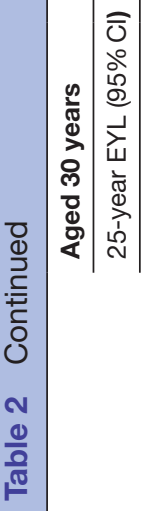

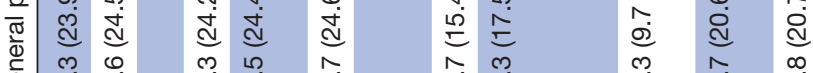

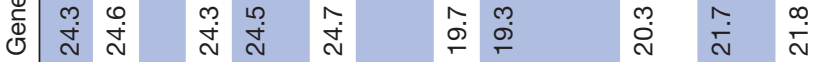

क़ ल

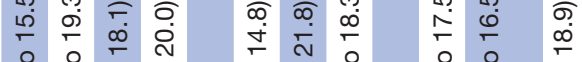

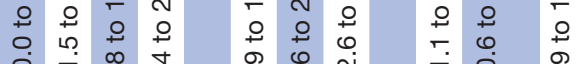

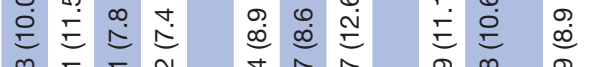

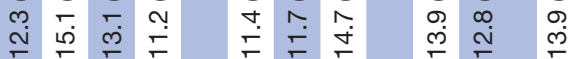

용 
improved considerably since the start of study period as a consequence of medical, diagnostic and treatment advances. $^{722}$

Several previous studies have linked multimorbidity with increased mortality among older adults. ${ }^{36-10} \mathrm{~A}$ metaanalysis including 26 studies of patients age 60 years or older reported an HR of 1.7 for patients with at least two diseases and 2.7 for those with at least three compared with people without multimorbidity. ${ }^{3}$ Similarly, the Emerging Risk Factor Collaboration found a 4-7 fold increased risk of death among patients (mean age: 53 years) with cardiometabolic multimorbidity compared with a reference group without multimorbidity. ${ }^{6}$ In line with our study, a number of previous groups used the CCI to identify multimorbidity, either with ${ }^{78}$ or without ${ }^{9}{ }^{10}$ an index disease. For example, Schmidt $e t a l^{7}$ found a 2.5fold higher 5-year mortality rate among stroke patients with a weighted CCI score of 3+ compared with stroke patients with a weighted CCI score of 0 .

In contrast to most previous literature on multimorbidity, we examined the prognosis in young and middleaged adults under aged 50 years. In line with current understanding, ${ }^{2}$ we found a steep socioeconomic gradient in YLLs attributable to multimorbidity, with YLLs because of low socioeconomic status increasing with the number of prevalent diseases. Although we compiled data on socioeconomic factors 2 years before baseline, reverse causality remains possible. ${ }^{23}$ Given that YLLs for patients who were 30 years old and in the low-income category were as high as or higher than YLLs for very high-income patients a decade older, reducing disparities in healthcare is obviously crucial. We did not examine associations of modifiable risk factors linked to socioeconomic status, such as tobacco smoking, excessive alcohol consumption, poor diet, high body mass index, hypertension and hyperlipidaemia. ${ }^{24}$ We also could not evaluate whether socioeconomic status itself was acting directly through complex mechanisms involving upstream factors ${ }^{25}$. Both of these questions require further investigation.

Our study also evaluated YLLs in relation to psychiatric conditions, a poorly understood area in relation to somatic multimorbidity, particularly in young and middle-aged adults. Psychiatric conditions increase in prevalence with increasing burden of physical ill health. ${ }^{2}$ Our findings that YLLs attributable to psychiatric conditions increased with an increasing number of prevalent diseases indicates an unmet need among those with these psychiatric conditions.

Healthcare systems lack an optimal infrastructure to properly care for patients with multimorbidity. Although these patients may be in contact with health services more frequently than those who have a single disease, management of multimorbidity is usually fragmented, as medical professionals are becoming increasingly specialised in single diseases or organs. ${ }^{26}$ Thus, improving coordination of care is a great challenge, particularly in light of the demographic changes that will lead to increasing numbers of patients with multiple conditions. ${ }^{2}$ 


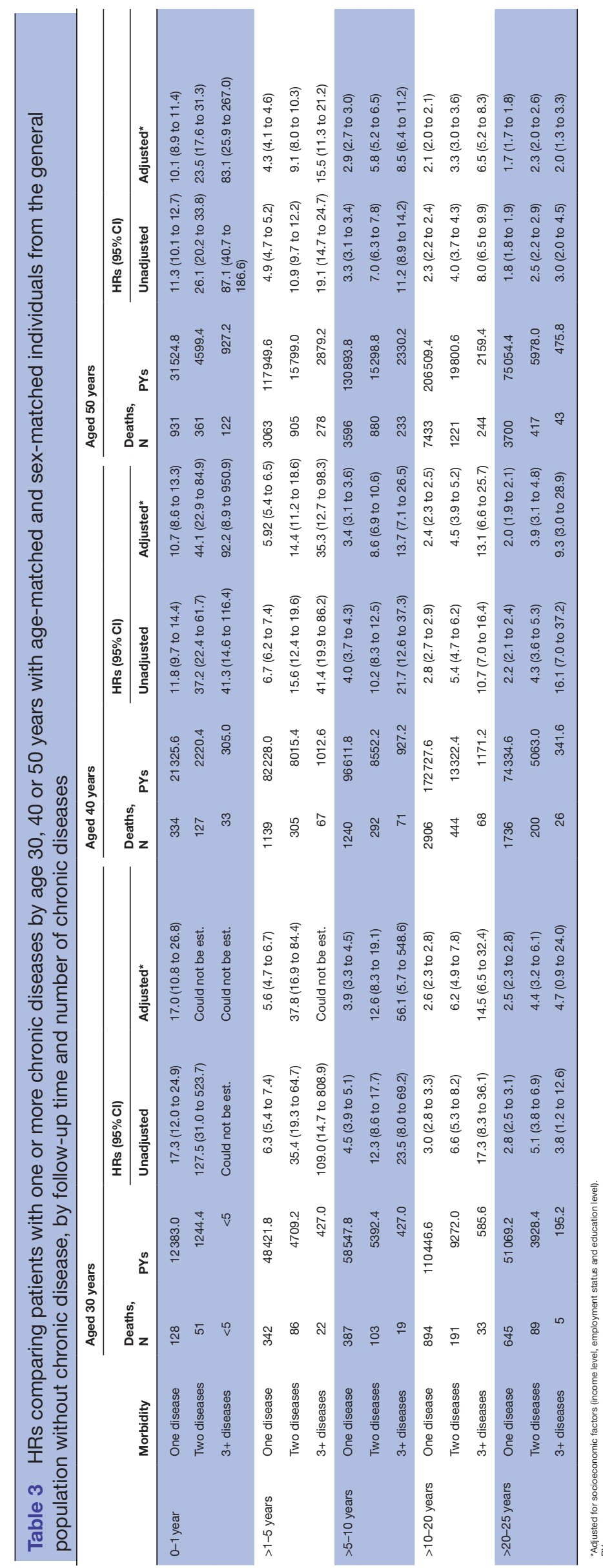


In conclusion, young and middle-aged patients hospitalised with one or more chronic diseases had increased mortality risk during 25 years of follow-up, compared with age-matched and sex-matched persons from the general population without chronic disease. The risk of death grew steadily with the number of chronic diseases and with age. Multimorbidity also added to the increased mortality among patients with low socioeconomic status.

Contributors AGO, NS and HTTS designed the study. EH-P and HTTS collected the data. NS and AGO reviewed the literature. AGO, NS and HTTS directed the analyses, which were carried out by BD. All authors participated in the discussion and interpretation of results. NS and AGO organised the writing and wrote the initial draft. All authors critically revised the manuscript for intellectual content and approved the final version. HTTS is the guarantor.

Funding This work was supported by a grant from The Lundbeck Foundation (grant no. R248-2017-521). The sponsor had no role in study design, data collection, analysis or interpretation of the data, writing of the manuscript or in the decision to submit the paper for publication. All authors had full access to the study data and had final responsibility for the decision to submit for publication.

Competing interests None declared.

Patient and public involvement Patients and/or the public were not involved in the design, or conduct, or reporting, or dissemination plans of this research.

Patient consent for publication Not required.

Provenance and peer review Not commissioned; externally peer reviewed.

Data availability statement № data are available.

Open access This is an open access article distributed in accordance with the Creative Commons Attribution Non Commercial (CC BY-NC 4.0) license, which permits others to distribute, remix, adapt, build upon this work non-commercially, and license their derivative works on different terms, provided the original work is properly cited, appropriate credit is given, any changes made indicated, and the use is non-commercial. See: http://creativecommons.org/licenses/by-nc/4.0/.

ORCID iD

Nils Skajaa http://orcid.org/0000-0001-8351-7133

\section{REFERENCES}

1 Ording AG, Sørensen HT. Concepts of comorbidities, multiple morbidities, complications, and their clinical epidemiologic analogs. Clin Epidemiol 2013;5:199-203.

2 Barnett K, Mercer SW, Norbury M, et al. Epidemiology of multimorbidity and implications for health care, research, and medical education: a cross-sectional study. Lancet 2012;380:37-43.

3 Nunes BP, Flores TR, Mielke Gl, et al. Multimorbidity and mortality in older adults: a systematic review and meta-analysis. Arch Gerontol Geriatr 2016;67:130-8.

4 Ryan A, Wallace E, O'Hara P, et al. Multimorbidity and functional decline in community-dwelling adults: a systematic review. Health Qual Life Outcomes 2015;13:168.
5 Bähler C, Huber CA, Brüngger B, et al. Multimorbidity, health care utilization and costs in an elderly community-dwelling population: a claims data based observational study. BMC Health Serv Res 2015;15:23.

6 Di Angelantonio E, Kaptoge S, Gillum RF, et al. Association of cardiometabolic multimorbidity with mortality. JAMA 2015:314:52-60.

7 Schmidt M, Jacobsen JB, Johnsen SP, et al. Eighteen-year trends in stroke mortality and the prognostic influence of comorbidity. Neurology 2014;82:340-50.

8 Corraini P, Szépligeti SK, Henderson VW, et al. Comorbidity and the increased mortality after hospitalization for stroke: a populationbased cohort study. J Thromb Haemost 2018;16:242-52.

9 Zeng C, Ellis JL, Steiner JF, et al. Assessment of morbidity over time in predicting health outcomes. Med Care 2014;52 Suppl 3:S52-9.

10 Wang CY, Baldwin L-M, Saver BG, et al. The contribution of longitudinal comorbidity measurements to survival analysis. Med Care 2009;47:813-21.

11 Pefoyo AJK, Bronskill SE, Gruneir A, et al. The increasing burden and complexity of multimorbidity. BMC Public Health 2015;15:415.

12 Pathirana TI, Jackson CA. Socioeconomic status and multimorbidity: a systematic review and meta-analysis. Aust N Z J Public Health 2018:42:186-94.

13 Schmidt M, Schmidt SAJ, Adelborg K, et al. The Danish health care system and epidemiological research: from health care contacts to database records. Clin Epidemiol 2019;11:563-91.

14 Schmidt M, Pedersen L, Sørensen HT. The Danish civil registration system as a tool in epidemiology. Eur J Epidemiol 2014;29:541-9.

15 Charlson ME, Pompei P, Ales KL, et al. A new method of classifying prognostic comorbidity in longitudinal studies: development and validation. J Chronic Dis 1987;40:373-83.

16 Schmidt M, Schmidt SAJ, Sandegaard JL, et al. The Danish national patient registry: a review of content, data quality, and research potential. Clin Epidemiol 2015;7:449-90.

17 Thygesen SK, Christiansen CF, Christensen S, et al. The predictive value of ICD-10 diagnostic coding used to assess Charlson comorbidity index conditions in the population-based Danish national Registry of patients. BMC Med Res Methodol 2011;11:83.

18 Heide-Jørgensen U, Adelborg K, Kahlert J, et al. Sampling strategies for selecting general population comparison cohorts. Clin Epidemiol 2018;10:1325-37.

19 Petersson F, Baadsgaard M, Thygesen LC. Danish registers on personal labour market affiliation. Scand J Public Health 2011;39:95-8.

20 Mors O, Perto GP, Mortensen PB. The Danish psychiatric central research register. Scand J Public Health 2011;39:54-7.

21 Frost L, Andersen LV, Johnsen SP, et al. Lost life years attributable to stroke among patients with nonvalvular atrial fibrillation: a nationwide population-based follow-up study. Neuroepidemiology 2007;29:59-65.

22 Schmidt M, Jacobsen JB, Lash TL, et al. 25 year trends in first time hospitalisation for acute myocardial infarction, subsequent short and long term mortality, and the prognostic impact of sex and comorbidity: a Danish nationwide cohort study. BMJ 2012;344:e356.

23 Garbarski D. Perceived social position and health: is there a reciprocal relationship? Soc Sci Med 2010;70:692-9.

24 Stringhini S, Sabia S, Shipley M, et al. Association of socioeconomic position with health behaviors and mortality. JAMA 2010;303:1159-66

25 Adler NE, Newman K. Socioeconomic disparities in health: pathways and policies. Health Aff 2002;21:60-76.

26 Doessing A, Burau V. Care coordination of multimorbidity: a scoping study. J Comorb 2015;5:15-28. 